\title{
The Influence of Rotational Training on Muscle Activity of Young Adults in Thermographic Imaging
}

\author{
Jolanta G. Zuzda ${ }^{1}$, Magdalena Topczewska ${ }^{2}$, \\ Piotr Borkowski ${ }^{3}$, Robert Latosiewicz ${ }^{4}$ \\ 1 Department of Tourist Economy, Faculty of Management, Bialystok University of Tech- \\ nology, Poland \\ 2 Faculty of Computer Science, Bialystok University of Technology, Poland \\ ${ }^{3}$ Department of Biocybernetics and Biomedical Engineering, Faculty of Mechanical En- \\ gineering, Bialystok University of Technology, Poland \\ 4 Department of Rehabilitation and Physiotherapy, Faculty of Health Sciences, Medical \\ University of Lublin, Poland
}

\begin{abstract}
The aim of this paper is to describe and assess the energeticmetabolic activity of selected muscles of upper and lower extremities during Rotational Training (RT). The influence of RT on temperature changes in the biceps and triceps brachii muscles as well as the quadriceps and biceps femoris muscles of healthy university students were verified, in addition to temperature differences between the left and right side before and after RT. The study was conducted on 18 subjects. RT was conducted in accordance with accepted forms of training methodology of collective fitness. An important part of RT was the performance of circular and rotational movements. Thermograms taken before and immediately after RT focused on 4 regions of selected agonists and synergists in the upper and lower body. The camera used was the infrared hand-held CEDIP Titanium 560M IR (USA), located at a distance of $10 \mathrm{~m}$ from the subject. After RT, median $T_{s k}$ (skin temperature) decreased in almost all of the examined ROIs, except for the left and right Qf (the quadriceps femoris, rectus femoris, and sartorius muscles) as well as the left $\mathrm{Tb}$ (triceps brachii) in female subjects. In male subjects, left and right $T_{s k}$ of $\mathrm{Qf}$ increased both for the left and right $\mathrm{Tb}$. Left-Right $\Delta T_{s k}$ (temperature difference) was statistically significant $(p<0.05)$ for $\mathrm{Of}, \mathrm{Bf}, \mathrm{Bb}, \mathrm{Tb}$ in female as well as male subjects. It was concluded that thermography is a non-invasive, safe, and low-cost method for the recording of physiological response of the skin to RT.
\end{abstract}

\section{Introduction}

Physical activity (PA) is a biological human need necessary to maintain good health. It should be a necessary component of lifestyle, shaping the functional and morphological characteristics of an organism (Corbin et al., 2009; Dwayer \& Davis, 2005; Starosta, 1997). PA plays a key role at all 
stages of human life (Griffin, 2006; Heszen, 2005). In the last years, there has been a noticeable increase in the interest in participation in health and fitness activities (Thompson, 2011). Regular moderate-intensity PA influences health and well-being, playing an important role in the prevention of various chronic diseases (Klavestrand \& Vingård, 2009; Warburton et al., 2006). Global Strategy for Adolescents' Health stresses that "Today we have both the knowledge and the opportunity to end preventable deaths among adolescents', to greatly improve their health and to bring about the transformative change needed to shape a more prosperous and sustainable future" (EWEC, 2015). An increase in PA is a public health priority in most developed countries (Cavill et al., 2006). Literature suggests that engaging in regular moderate-intensity PA is one of the most beneficial ways to improve physical, emotional, and psychological health (Cavill et al., 2006; Hass et al., 2001; Klavestrand \& Vingård, 2009; Liu et al., 2003; Warburton et al., 2006).

A program that can be of much benefit to the exercising person is one with elements of rotational movements. Rotational exercises consist of simple movements that require slow rotation of the wrists, arms, torso, and legs together with other "normal" movements during the exercise. The focus of Rotational Training (RT) is to improve coordination, body balance, mobility and motor efficiency of the body and, consequently, help achieve a better health status (Coulter, 2010; Zuzda et al., 2013a; Zuzda et al., 2013b).

The physiological effects of RT are reasonably well-explored in terms of cardiovascular and musculoskeletal responses. However, local temperature responses, specifically during RT, have not yet been described. As a matter of fact, to the authors' knowledge, no study has been performed that would examine the effects of the training programme in question on skin temperature $\left(T_{s k}\right)$ of the proximal parts of extremities during and after RT.

Hence, this study was designed with a twofold aim. Firstly, an attempt was made to verify whether RT has an impact on skin temperature changes $\left(T_{s k}\right)$ in the biceps and triceps brachii muscles as well as the quadriceps and biceps femoris muscles of healthy university students. Secondly, the occurrence of left-right side temperature differences $\left(\Delta T_{s k}\right)$ before and after RT was verified.

\section{Materials and Methods}

The study was conducted at Bialystok University of Technology, Bialystok, Poland (BUT) and was approved by the local Bioethics Committee. The research was performed on a group of volunteers: 9 women $(20.02 \pm 0.4$ 
years old) and 9 men (19.89 \pm 0.7 years old) The inclusion criterion was good general health status, which would allow the students to perform RT. In addition, before training, all subjects gave informed consent regarding the study procedures.

Each subject's body weight was measured on a scale with a resolution of $100 \mathrm{~g}$. The subject's height was measured by means of WPT 100/200 OW stadiometer (Wagi Elektroniczne, Poland). BMI was automatically calculated with the use of the software provided by the manufacturer. Vital lung capacity was measured using a mechanical spirometer (Barens, Warsaw, PL) and expressed in millilitres. Each measurement was taken twice and averaged. Systolic and diastolic blood pressure were measured pre- and posttraining with the use of an electronic blood pressure monitor (Panasonic EW 3106). The short version of the International Physical Activity Questionnaire (PAR-Q +) (http://eparmed-x.appspot.com) was used to assess the students for whom PA might be inappropriate.

RT was conducted in accordance with accepted forms of training methodology of collective fitness (Zuzda \& Latosiewicz, 2010). The training session started with a warm-up (10 minutes), in order to prepare the body and mind for a more strenuous activity and minimize the risk of injury. The main training part (40 minutes) consisted of simple symmetrical movements whose purpose was to build and enhance all body parts. An important part of the program was the performance of circular and rotational movements. The ultimate aim of RT was to ensure the correct functioning of the entire human body through functional strength and stabilization training of the human motion system. All exercises and positions during RT used different muscles of the body at the same time. Cool-down with breathing and stretching exercises (10 minutes) was the last part of RT. The sessions were supervised by the same instructor under standardized conditions regarding artificial light, a constant temperature of $21-22^{\circ} \mathrm{C}$, and relative humidity (50\%). In the morning, the subjects recorded their individual resting heart rate (HR). These values were used to calculate their maximum HR, establishing the heart rate limits for the study (Whaley et al., 1992). The intensity of exercise increased during RT training in the way shown in Table 1. The subjective intensity of RT was measured using the Borg scale of perceived exertion (from 6 to 20).

A thermographic camera (CEDIP Titanium 560M IR, USA) was used in the study. The integrated resolution of the camera was $640 \times 512$ pixels, with an accuracy of $1^{\circ} \mathrm{C}$ of absolute temperature and an emissivity of 0.98 . The camera was placed perpendicularly to the scanned surface. $T_{s k}$ data from selected regions of interest (ROI) was obtained from anatom- 
Table 1. Working load intensity parameters during the main part of RT

\begin{tabular}{|l|c|}
\hline \multicolumn{2}{|c|}{ Main part of RT } \\
\hline Intensity & Beginners \\
\hline Borg scale & $10-12$ \\
\hline \% HRmax* & $50 \%-60 \%$ \\
\hline
\end{tabular}

* \%HRmax - Maximum Heart Rate

Table 2. Skin areas of selected muscles, their parts or groups (regions of interest $=$ ROIs)

\begin{tabular}{|c|l|}
\hline $\begin{array}{c}\text { Skin areas } \\
\text { abbreviation }\end{array}$ & $\begin{array}{c}\text { Muscles, their parts } \\
\text { or groups (ROI) }\end{array}$ \\
\hline $\mathrm{Bb}$ & m. biceps brachii \\
\hline $\mathrm{Tb}$ & m. triceps brachii \\
\hline $\mathrm{Qf}$ & $\begin{array}{l}\text { m. quadriceps femoris } \\
\text { m. rectus femoris } \\
\text { m. sartorius }\end{array}$ \\
\hline $\mathrm{Bf}$ & $\begin{array}{l}\text { m. biceps femoris } \\
\text { m. semitendinosus }\end{array}$ \\
\hline
\end{tabular}

ical regions using the criteria set out by Novotny et al. (2015) (Table 2). The following ROIs were set: on the front side of the limbs - the biceps brachii muscles $(\mathrm{Bb})$ and the quadriceps femoris, rectus femoris, and sartorius muscles (Qf); on the back side of the limbs - the triceps brachii muscles $(\mathrm{Tb})$ and the biceps femoris muscles (Bf). Measurements were taken symmetrically on the right and the left side to provide additional evaluation of temperature differences $\left(\Delta T_{s k}\right)$ at the ROIs on both the right and the left side (Figure 1).

Analysis of temperature changes prior to and after RT. For the analysis of thermograms, a relative temperature indicator and normalized units were defined. The relative temperature of an area is calculated with the use of the following formula:

$$
R T_{s k}=T / A T\left[{ }^{\circ} \mathrm{C} /{ }^{\circ} \mathrm{C}=\mathrm{nu}\right],
$$

where: $R T_{s k}$ - relative temperature of a particular area in normalized units (nu), $T$ - temperature of a particular area in centigrade $\left({ }^{\circ} \mathrm{C}\right), A T-$ average temperature of all 8 measured areas in centigrade $\left({ }^{\circ} \mathrm{C}\right)$. 


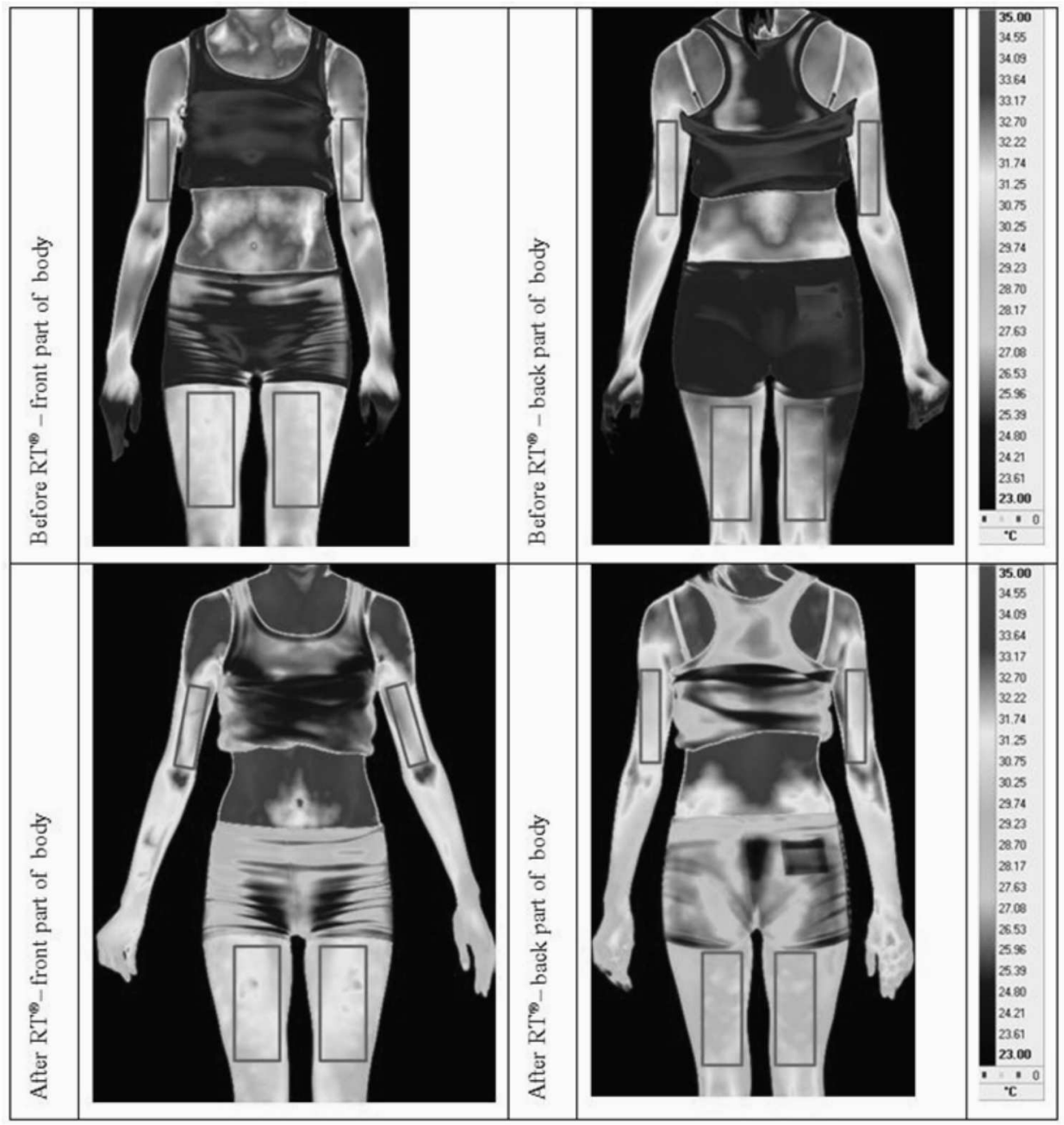

Figure 1. Examples of thermograms with selected muscle areas: before RT (left-hand side) and immediately after RT (right-hand side); colours display range from 28 to $38^{\circ} \mathrm{C}$

The thermograms were taken in the standing and static positions, of the front and the back of the body, prior to RT (after a 15-minute adaptation in the hall) and immediately after (approx. 30-60 seconds) RT. To visualize the temperatures on the skin surface, a high-contrast colour scale was used. The thermograms were analysed using the original 5.80.005 software (Altair Engineering, Inc., USA). 
Statistical Analysis. The means and standard deviations, the median and the range, were calculated for the demographic data obtained from all participants. For basic data characteristics, the Shapiro-Wilk test was used for the analysis of normal distribution. The data obtained from the thermograms, taken at each of the two instances specified above, was averaged in order to provide a unique score for each participant. Temperature changes between pre-training and post-training were calculated using the Wilcoxon test and median values were reported. A value of $p<0.05$ was considered as statistically significant. Statistica 12.5 software (StatSoft Polska, Poland) was used for the analysis.

\section{Results}

The mean age of subjects at the beginning of the study was $20.2 \pm 0.4$ years for female subjects and $19.9 \pm 0.7$ for male subjects. Detailed morphological and physiological characteristics of the participants are shown in Table 3.

Table 3. Morphological and physiological characteristics of participants at the beginning of the study

\begin{tabular}{|c|c|c|c|c|c|c|c|c|c|}
\hline Gender & Statistics & $\begin{array}{c}\text { Age } \\
\text { [year] }\end{array}$ & $\begin{array}{c}\text { Height } \\
{[\mathrm{m}]}\end{array}$ & $\begin{array}{c}\text { Body mass } \\
{[\mathrm{kg}]}\end{array}$ & $\begin{array}{c}\text { BMI } \\
{\left[\mathrm{kg} / \mathrm{m}^{2}\right]}\end{array}$ & $\begin{array}{l}\text { WC } \\
{[\mathrm{cm}]}\end{array}$ & $\begin{array}{c}\mathrm{SBP} \\
{[\mathrm{mm} \mathrm{Hg}]}\end{array}$ & $\begin{array}{c}\text { DPB } \\
{[\mathrm{mm} \mathrm{Hg}]}\end{array}$ & $\begin{array}{l}\mathrm{VC} \\
{[\mathrm{ml}]}\end{array}$ \\
\hline \multirow{3}{*}{$\begin{array}{l}\text { Female } \\
(\mathrm{n}=9)\end{array}$} & $\begin{array}{l}\text { Mean } \\
\pm \text { Std }\end{array}$ & $\begin{array}{l}20.20 \\
\pm 0,44\end{array}$ & $\begin{array}{c}1.67 \\
\pm 0.04\end{array}$ & $\begin{array}{l}59.93 \\
\pm 4.51\end{array}$ & $\begin{array}{l}21.49 \\
\pm 1.46\end{array}$ & $\begin{array}{l}73.11 \\
\pm 4.88\end{array}$ & $\begin{array}{l}125.56 \\
\pm 8.61\end{array}$ & $\begin{array}{l}71.00 \\
\pm 3.69\end{array}$ & $\begin{array}{l}5500.00 \\
\pm 604.2\end{array}$ \\
\hline & Min & 20.00 & 1.61 & 54.00 & 19.03 & 63.00 & 110.00 & 66.00 & 4700.00 \\
\hline & Max & 21.00 & 1.73 & 64.40 & 24.00 & 80.00 & 136.00 & 77.00 & 6200.00 \\
\hline \multirow{3}{*}{$\begin{array}{c}\text { Male } \\
(\mathrm{n}=9)\end{array}$} & $\begin{array}{l}\text { Mean } \\
\pm \text { Std }\end{array}$ & $\begin{array}{l}19.90 \\
\pm 0.68\end{array}$ & $\begin{array}{c}1.82 \\
\pm 0.06\end{array}$ & $\begin{array}{l}75.11 \\
\pm 0.56\end{array}$ & $\begin{array}{l}22.71 \\
\pm 1.56\end{array}$ & $\begin{array}{l}84.89 \\
\pm 4.04\end{array}$ & $\begin{array}{l}130.00 \\
\pm 4.85\end{array}$ & $\begin{array}{l}75.78 \\
\pm 6.67\end{array}$ & $\begin{array}{l}3611.00 \\
\pm 395.11\end{array}$ \\
\hline & Min & 19.00 & 1.71 & 65.00 & 20.29 & 63.00 & 122.00 & 66.00 & 2800.00 \\
\hline & Max & 21.00 & 1.92 & 87.00 & 25.69 & 90.00 & 135.00 & 83.00 & 4100.00 \\
\hline
\end{tabular}

$\mathrm{n}$ - number of subject; std - standard deviation; BMI - Body Mass Index.; WC - Waist Circumference; DPB - Diastolic Blood Pressure; SBP - Systolic blood Pressure; VC Vital Capacity

After RT, median $T_{s k}$, mainly on both sides, was lower than before RT in female subjects, except for the left and right Qf where $T_{s k}$ increased (from $30.2^{\circ} \mathrm{C}$ to $31.2^{\circ} \mathrm{C} ; p<0.05$, and from $30.5^{\circ} \mathrm{C}$ to $31.1^{\circ} \mathrm{C} ; p<0.05$, respectively) and for the left $\mathrm{Tb}$ (from $29.45^{\circ} \mathrm{C}$ to $29.6^{\circ} \mathrm{C} ; p<0.05$ ). For 
male subjects, median $T_{s k}$ after RT was lower than before RT, except for the left and right $\mathrm{Qf}$ where $T_{s k}$ increased (from $30.5^{\circ} \mathrm{C}$ to $31.1^{\circ} \mathrm{C} ; p<0.05$, from $30.7^{\circ} \mathrm{C}$ to $31.1^{\circ} \mathrm{C} ; p<0.05$, respectively) and for the left and right $\mathrm{Tb}$ (from $31.2^{\circ} \mathrm{C}$ to $31.8^{\circ} \mathrm{C}$; from $31.6^{\circ} \mathrm{C}$ to $31.9^{\circ} \mathrm{C} ; p<0.05$, respectively) (Table 4 ).

Table 4. Skin temperature $\left({ }^{\circ} \mathrm{C}\right)$ of muscles areas before and after RT

\begin{tabular}{|c|c|c|c|c|c|c|c|c|c|c|c|c|}
\hline \multirow{2}{*}{$\mathrm{F} / \mathrm{M}$} & \multirow{2}{*}{ Muscle } & \multirow{2}{*}{$\begin{array}{c}\text { Before/ } \\
\text { After }\end{array}$} & \multicolumn{3}{|c|}{ Left side } & \multicolumn{3}{|c|}{ Right side } & \multicolumn{4}{|c|}{$\mathrm{L}-\mathrm{R} \Delta T_{s k}$} \\
\hline & & & $\mathrm{M}_{\mathrm{e}}$ & $\mathrm{Q}_{1}$ & $\mathrm{Q}_{3}$ & $\mathrm{M}_{\mathrm{e}}$ & $\mathrm{Q}_{1}$ & $\mathrm{Q}_{3}$ & $\mathrm{M}_{\mathrm{e}}$ & $\mathrm{Q}_{1}$ & $\mathrm{Q}_{3}$ & $W_{R-L}$ \\
\hline \multirow{8}{*}{$\mathrm{F}$} & \multirow{2}{*}{ Qf } & before & 30.2 & 30.0 & 30.5 & 30.5 & 30.0 & 30.8 & -0.3 & -0.3 & 0.5 & $0.0001^{*}$ \\
\hline & & after & 31.2 & 30.7 & 31.7 & 31.1 & 30.7 & 31.6 & 0.1 & -0.4 & 0.4 & $0.0090^{*}$ \\
\hline & \multirow{2}{*}{$\mathrm{Bf}$} & before & 30.8 & 29.9 & 31.8 & 30.8 & 29.4 & 31.7 & 0.0 & -0.8 & 0.1 & $0.0001^{*}$ \\
\hline & & after & 30.5 & 29.7 & 32.2 & 30.4 & 29.7 & 32.0 & 0.1 & -0.5 & 0.3 & $0.0001^{*}$ \\
\hline & \multirow{2}{*}{$\mathrm{Bb}$} & before & 31.4 & 31.1 & 31.9 & 31.4 & 30.9 & 32.0 & 0.0 & -0.5 & 0.4 & $0.0001^{*}$ \\
\hline & & after & 31.2 & 30.5 & 31.9 & 31.2 & 30.6 & 31.7 & 0.0 & -0.5 & 0.5 & $0.0085^{*}$ \\
\hline & \multirow{2}{*}{$\mathrm{Tb}$} & before & 29.4 & 28.8 & 30.0 & 29.4 & 28.9 & 30.2 & 0.0 & -0.6 & 0.3 & $0.0001^{*}$ \\
\hline & & after & 29.6 & 29.2 & 30.1 & 29.3 & 28.7 & 30.2 & 0.3 & -0.7 & 0.2 & $0.0001^{*}$ \\
\hline \multirow{8}{*}{ M } & \multirow{2}{*}{ Qf } & before & 30.5 & 30.1 & 31.0 & 30.7 & 30.3 & 31.3 & -0.2 & -0.2 & 0.5 & $0.0001^{*}$ \\
\hline & & after & 31.1 & 30.2 & 31.7 & 31.1 & 30.2 & 31.7 & 0.0 & -0.5 & 0.6 & $0.0001^{*}$ \\
\hline & \multirow{2}{*}{$\mathrm{Bf}$} & before & 31.5 & 30.9 & 32.1 & 31.6 & 30.8 & 32.3 & -0.1 & -0.4 & 0.5 & 0.0001* \\
\hline & & after & 31.1 & 30.5 & 31.6 & 31.0 & 30.3 & 31.7 & 0.1 & -0.4 & 0.4 & 0.0028* \\
\hline & \multirow{2}{*}{$\mathrm{Bb}$} & before & 32.7 & 31.8 & 33.4 & 32.8 & 31.8 & 33.7 & -0.1 & -0.2 & 0.5 & $0.0001^{*}$ \\
\hline & & after & 32.6 & 31.2 & 33.2 & 32.3 & 31.2 & 33.2 & 0.3 & -0.7 & 0.6 & 0.0770 \\
\hline & \multirow{2}{*}{$\mathrm{Tb}$} & before & 31.2 & 30.7 & 32.6 & 31.6 & 30.5 & 32.5 & -0.4 & -0.6 & 0.7 & 0.9180 \\
\hline & & after & 31.8 & 30.6 & 32.8 & 31.9 & 30.8 & 32.4 & -0.1 & -0.5 & 0.5 & 0.2610 \\
\hline
\end{tabular}

Key: before/after - before or after TR, $\mathrm{M}_{\mathrm{e}}-$ median; $\mathrm{Q}_{1}-1$ st quartile; $\mathrm{Q}_{3}-3$ rd quartile; $\mathrm{R}-\mathrm{L}$ - right-left; $\mathrm{W}_{\mathrm{R}-\mathrm{L}}$ - result of Willcoxon test of left-right differences; $\mathrm{F}$ - female; $\mathrm{M}-$ male $^{*}-p<0.05$

Left-Right $\Delta T_{s k}$ was statistically significant $(p<0.05)$ for Of, Bf, Bb and $\mathrm{Tb}$ in female subjects and did not exceed $0.3^{\circ} \mathrm{C}$. In male subjects, rightleft $\Delta T_{s k}$ was statistically significant $(p<0.05)$, except for $\mathrm{Tb}$ before and after $\mathrm{RT}(p=0.918 ; p=0.261$, respectively) and $\mathrm{Bb}$ after $\mathrm{RT}(p=0.077)$, and did not exceed $0.4^{\circ} \mathrm{C}$ (Table 4 ).

Table 5 shows median $\Delta T_{s k}$ left and $\Delta T_{s k}$ right after RT. The decrease in median values for $\Delta T_{s k}$ right for the upper and lower extremities is statistically significant, except for $\Delta T_{s k}$ Qf where $\Delta T_{s k}$ increased $\left(0.6^{\circ} \mathrm{C}\right.$ and $0.4^{\circ} \mathrm{C} ; p<0.05$, in female and male subjects, respectively) as well as $\mathrm{Tb}$ in male subjects $\left(0.3^{\circ} \mathrm{C} ; p<0.05\right)$. 
Table 5. $\Delta T_{s k}$ left and $\Delta T_{s k}$ right differences between ROIs after vs. before 60 minutes; RT comparison performed with the use of the Wilcoxon test

\begin{tabular}{|c|c|c|c|c|c|}
\hline \multirow[b]{2}{*}{$\mathrm{F} / \mathrm{M}$} & \multirow[b]{2}{*}{ Muscle } & \multicolumn{2}{|c|}{ Left side } & \multicolumn{2}{|c|}{ Right side } \\
\hline & & $\begin{array}{l}\text { Median } \Delta T_{s k} \\
\text { (after) minus } \\
\text { (before) }\left({ }^{\circ} \mathrm{C}\right)\end{array}$ & $\begin{array}{c}\text { Wilcoxon } \\
\text { (after) minus } \\
\text { (before) (p) }\end{array}$ & $\begin{array}{l}\text { Median } \Delta T_{s k} \\
\text { (after) minus } \\
\text { (before) }\left({ }^{\circ} \mathrm{C}\right)\end{array}$ & $\begin{array}{c}\text { Wilcoxon } \\
\text { (after) minus } \\
\text { (before) }(\mathrm{p})\end{array}$ \\
\hline \multirow{4}{*}{$\mathrm{F}$} & Qf & 1.0 & 0.0001 & 0.6 & 0.0001 \\
\hline & $\mathrm{Bf}$ & -0.3 & 0.0001 & -0.4 & 0.0001 \\
\hline & $\mathrm{Bb}$ & -0.2 & 0.0001 & -0.2 & 0.0004 \\
\hline & $\mathrm{Tb}$ & 0.2 & 0.0001 & -0.1 & 0.0001 \\
\hline \multirow{4}{*}{$\mathrm{M}$} & Qf & 0.6 & 0.0001 & 0.4 & 0.0001 \\
\hline & $\mathrm{Bf}$ & -0.4 & 0.0001 & -0.6 & 0.0001 \\
\hline & $\mathrm{Bb}$ & -0.1 & 0.0001 & -0.5 & 0.0001 \\
\hline & $\mathrm{Tb}$ & 0.6 & 0.0001 & 0.3 & 0.0001 \\
\hline
\end{tabular}

Key: $p$ - level of significance during the Wilcoxon pair difference test; the abbreviations used for the areas are clarified in the section describing methods (Table 2)

The decrease in median $\Delta T_{s k}$ for the upper left and lower left extremities is statistically significant for $\mathrm{Bf}, \mathrm{Bb}$ in female and male subjects $\left(-0.3^{\circ} \mathrm{C}\right.$, $-0.2^{\circ} \mathrm{C}, p<0.05 ;-0.4^{\circ} \mathrm{C},-0.1^{\circ} \mathrm{C}, p<0.05$, respectively), while the increase is statistically significant for $\mathrm{Qf}$ and $\mathrm{Tb}$ in both groups of subjects $\left(1.0^{\circ} \mathrm{C}\right.$, $0.6^{\circ} \mathrm{C}, p<0.05$ and $0.2^{\circ} \mathrm{C}, 0.6^{\circ} \mathrm{C}, p<0.05$, respectively).

Table 6 presents the calculated relative $T_{s k}$ of ROIs, the results of the Wilcoxon test and their $T_{s k}$ values before and after RT. After RT, there was a relative decrease in $T_{s k}$ mainly on the right and the left side in the ROIs of $\mathrm{Bf}$ and $\mathrm{Bb}$, in male and female subjects, as well as right side $\mathrm{Tb}$ in female subjects. On the contrary, there was a relative increase in $T_{s k}$ on the right and the left side in the ROIs of Qf in female subjects; Tb on the right and the left side in male subjects, and $\mathrm{Tb}$ on the left side in female subjects.

Table 6. Relative temperature $R T_{s k}$ of muscle areas before and after RT $(n=18)$

\begin{tabular}{|c|c|c|c|c|c|c|c|c|c|c|}
\hline \multirow{2}{*}{ F/M } & \multirow{3}{*}{ Region } & \multirow{5}{*}{ Side } & \multicolumn{5}{|c|}{ Relative temperature [nu] } & \multirow{3}{*}{$p$} & \multirow{2}{*}{$\begin{array}{c}\text { Spearman } \\
\text { test (R) }\end{array}$} \\
\cline { 4 - 9 } & & & $\mathrm{M}_{\mathrm{e}}$ & $\mathrm{Q}_{1}$ & $\mathrm{Q}_{3}$ & $\mathrm{M}_{\mathrm{e}}$ & $\mathrm{Q}_{1}$ & $\mathrm{Q}_{3}$ & & \\
\hline \multirow{2}{*}{$\mathrm{F}$} & \multirow{2}{*}{$\mathrm{Qf}$} & $\mathrm{R}$ & 0.982 & 0.966 & 0.990 & 1.000 & 0.988 & 1.015 & $<0.0001$ & 0.095 \\
\cline { 4 - 9 } & & $\mathrm{L}$ & 0.971 & 0.964 & 0.981 & 1.002 & 0.988 & 1.015 & $<0.0001$ & 0.262 \\
\hline
\end{tabular}


The Influence of Rotational Training on Muscle Activity of Young Adults...

\begin{tabular}{|c|c|c|c|c|c|c|c|c|c|c|}
\hline \multirow{3}{*}{$\mathrm{F} / \mathrm{M}$} & \multirow{3}{*}{ Region } & \multirow{3}{*}{ Side } & \multicolumn{6}{|c|}{ Relative temperature [nu] } & \multirow{3}{*}{$p$} & \multirow{3}{*}{$\begin{array}{c}\text { Spearman } \\
\text { test }(\mathrm{R})\end{array}$} \\
\hline & & & \multicolumn{3}{|c|}{ Before RT } & \multicolumn{3}{|c|}{ After RT } & & \\
\hline & & & $\mathrm{M}_{\mathrm{e}}$ & $\mathrm{Q}_{1}$ & $\mathrm{Q}_{3}$ & $\mathrm{M}_{\mathrm{e}}$ & $\mathrm{Q}_{1}$ & $\mathrm{Q}_{3}$ & & \\
\hline \multirow{6}{*}{$\mathrm{F}$} & \multirow{2}{*}{$\mathrm{Bf}$} & $\mathrm{R}$ & 0.991 & 0.945 & 1.019 & 0.978 & 0.953 & 1.030 & $<0.0001$ & 0.799 \\
\hline & & $\mathrm{L}$ & 0.991 & 0.961 & 1.023 & 0.982 & 0.956 & 1.035 & $<0.0001$ & 0.790 \\
\hline & \multirow{2}{*}{$\mathrm{Bb}$} & $\mathrm{R}$ & 1.010 & 0.995 & 1.029 & 1.003 & 0.982 & 1.020 & $<0.0001$ & 0.676 \\
\hline & & $\mathrm{L}$ & 1.009 & 1.000 & 1.024 & 1.003 & 0.981 & 1.024 & $<0.0001$ & 0.486 \\
\hline & \multirow{2}{*}{$\mathrm{Tb}$} & $\mathrm{R}$ & 0.946 & 0.926 & 0.964 & 0.941 & 0.921 & 0.969 & $=0.0005$ & 0.699 \\
\hline & & $\mathrm{L}$ & 0.945 & 0.927 & 0.971 & 0.951 & 0.949 & 0.969 & $<0.0001$ & 0.656 \\
\hline \multirow{8}{*}{ M } & \multirow{2}{*}{ Qf } & $\mathrm{R}$ & 0.987 & 0.973 & 1.006 & 0.998 & 0.972 & 1.018 & $<0.0001$ & 0.377 \\
\hline & & $\mathrm{L}$ & 0.980 & 0.969 & 0.996 & 0.998 & 0.969 & 1.019 & $<0.0001$ & 0.374 \\
\hline & \multirow{2}{*}{$\mathrm{Bf}$} & $\mathrm{R}$ & 1.014 & 0.991 & 1.038 & 0.997 & 0.973 & 1.019 & $<0.0001$ & 0.564 \\
\hline & & $\mathrm{L}$ & 1.012 & 0.994 & 1.031 & 0.998 & 0.980 & 1.014 & $<0.0001$ & 0.464 \\
\hline & \multirow{2}{*}{$\mathrm{Bb}$} & $\mathrm{R}$ & 1.055 & 1.023 & 1.084 & 1.038 & 1.002 & 1.066 & $<0.0001$ & 0.700 \\
\hline & & $\mathrm{L}$ & 1.050 & 1.021 & 1.074 & 1.047 & 1.003 & 1.067 & $<0.0001$ & 0.746 \\
\hline & \multirow{2}{*}{$\mathrm{Tb}$} & $\mathrm{R}$ & 1.016 & 0.980 & 1.046 & 1.023 & 0.990 & 1.043 & $<0.0001$ & 0.078 \\
\hline & & $\mathrm{L}$ & 1.004 & 0.986 & 1.047 & 1.017 & 0.983 & 1.055 & $<0.0001$ & 0.784 \\
\hline
\end{tabular}

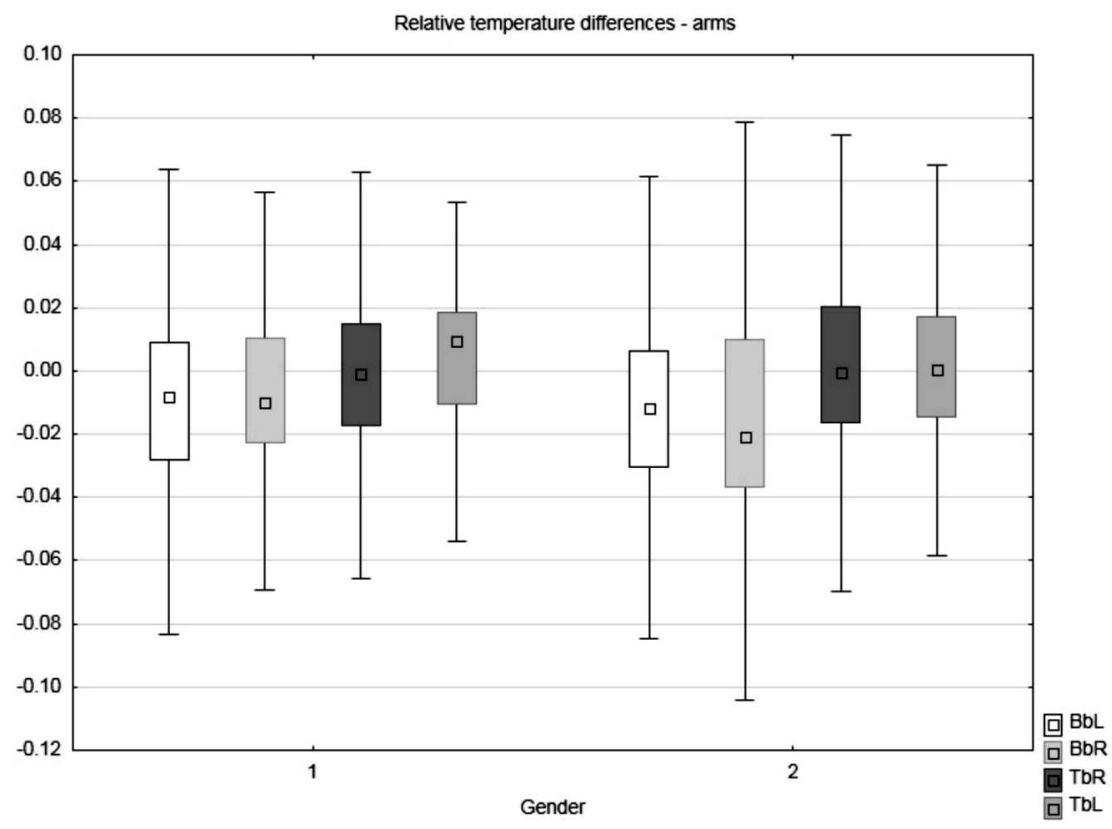

Figure 2. Changes in relative $T_{s k}$ in upper extremities for male (1) and female (2) subjects before and after RT 


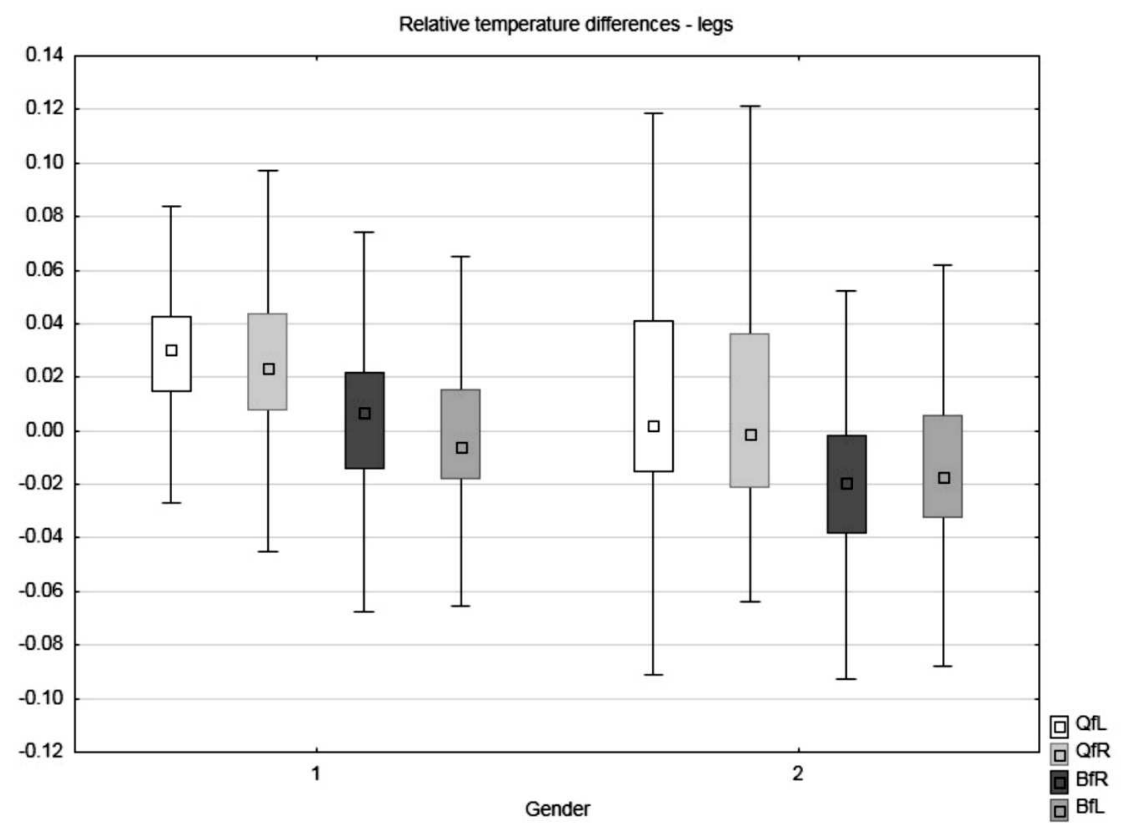

Figure 3. Changes in relative $T_{s k}$ in lower extremities for male (1) and female (2) subjects before and after RT

A graphic overview of changes in relative $T_{s k}$ before and after RT in ROIs is presented in Figure 2 and Figure 3.

\section{Discussion}

Studies of thermal response to PA have reported both decreases and increases in $T_{s k}$ immediately following exercise (Fernández-Cuevas et al., 2015). In the authors' study, thermographic data (Table 4) indicates that median $T_{s k}$ after RT decreases in almost all of the examined ROIs, except for the left and right Qf, where $T_{s k}$ increases from $30.2^{\circ} \mathrm{C}$ to $31.2^{\circ} \mathrm{C} ; p<0.05$, from $30.5^{\circ} \mathrm{C}$ to $31.1^{\circ} \mathrm{C}$; respectively $(p<0.05)$, and for the left $\mathrm{Tb}$, with an increase from $29.5^{\circ} \mathrm{C}$ to $29.6^{\circ} \mathrm{C}$, respectively $(p<0.05)$, in female subjects. In male subjects, the left and right $T_{s k}$ of Qf increased from $30.5^{\circ} \mathrm{C}$ to $31.1^{\circ} \mathrm{C}$ and from $30.7^{\circ} \mathrm{C}$ to $31.1^{\circ} \mathrm{C}$, respectively $(p<0.05)$, whereas for the left and right $\mathrm{Tb}$ the increase was from $31.2^{\circ} \mathrm{C}$ to $31.8^{\circ} \mathrm{C}$ and from $31.6^{\circ} \mathrm{C}$ to $31.9^{\circ} \mathrm{C}$, respectively $(p<0.05)$. In the authors' opinion, the decrease in $T_{s k}$ after RT was due to a prolonged act of sweating, the physiological effect of parasympathetic function. On the other hand, as stressed by 
Chudecka and Lubkowska (2012), the higher overall performance and stress tolerance caused by RT could also be the factors that enabled better heat distribution during exercise and a quicker return to normal body temperature during restitution. The authors' data is in agreement with the data provided by other researchers.

Chudecka and Lubkowska (2010) recorded drops in $T_{s k}$ in handball players, which were higher on the front surfaces of their upper extremities. A study performed by Merla et al. (2010) shows drops in $T_{s k}$ by $3-$ $5^{\circ} \mathrm{C}$ in the total body area of runners after run interruption, and that thighs and forearms exhibited the earliest response. In the present study, $T_{s k}$ change was as little as $0.0-0.9^{\circ} \mathrm{C}$. In the authors' opinion, the value was smaller than in the case of running due to a smaller RT intensity. Coh and Sirok (2007) concluded that $T_{s k}$ during PA increases and stabilizes at a higher level, in proportion to the intensity of exercise. Changes in surface temperature can provide information about the efficiency of the systems that removes endogenous heat generated by PA (Chudecka \& Lubkowska, 2010).

Researches (Fernández-Cuevas et al., 2015; Zaproudina, 2012) stress that gender may influence $T_{s k}$ patterns. Three reasons could be given to explain the differences: the first is the menstrual cycle, the second is subcutaneous fat, and the third is the metabolic rate. A higher upper body $T_{s k}$ was demonstrated for women (Chudecka \& Lubkowska, 2015), in the back area (Hashiguchi et al., 2010), in the rectal, and pectoralis muscle areas; while lower upper body $T_{s k}$ was demonstrated in the fingertips of young females compared to males (Isii et al., 2007). In the authors' study, thermographic data (Table 4) indicated that before and after RT the median $T_{s k}$ was lower in almost all of the examined ROIs in females compared to males, except for the left and right Qf after RT. These findings indicate that thermoregulatory responses in skin blood flow may be gender-dependent. In the authors' opinion, due to notable variations of $T_{s k}$ in different ROIs in male and female subjects, further research is needed to establish how gender may influence the $T_{s k}$ pattern during healthy training.

Asymmetry is the most important factor to consider in every study that uses thermography. The left-right side skin temperature differences in healthy subjects are nearly $0^{\circ} \mathrm{C}$ (Kenney \& Munce, 2003). A constant core body temperature is vital to preserve homeostasis, i.e. the relatively constant environment needed to maintain the functions and composition of body fluids and tissues. Changes in the core temperature of more than a few degrees either way is a clear indication of a physical dysfunction, and temperature changes outside this range may disrupt the essential chemical pro- 
cesses within the body (Jones \& Plassmann, 2002). Hildebrandt et al. (2010) stated that a difference of more than $1^{\circ} \mathrm{C}$ between the sides of the body may indicate a pathophysiological process. On the other hand, Uematsu (1985) stressed that in normal persons, skin temperature differences between the sides of the body is only $0.24 \pm 0.073^{\circ} \mathrm{C}$. In contrast, in patients with peripheral nerve injury, the temperature of the skin innervated by the damaged nerve deviates by an average of $1.55^{\circ} \mathrm{C}$. Vardasca et al. (2012) showed that in healthy subjects the highest $\Delta T_{s k}$ was at most $0.4^{\circ} \mathrm{C} \pm 0.3^{\circ} \mathrm{C}$ in total body views and $0.4^{\circ} \mathrm{C} \pm 0.15^{\circ} \mathrm{C}$ in regional views.

In the authors' study, it was found that left-right $\Delta T_{s k}$ was statistically significant $(p<0.05)$ for $\mathrm{Of}, \mathrm{Bf}, \mathrm{Bb}$ and $\mathrm{Tb}$ in female subjects and did not exceed $0.3^{\circ} \mathrm{C}$. On the contrary, in male subjects, right-left $\Delta T_{s k}$ was statistically significant $(p<0.05)$, except for Tb before and after RT ( $p=$ 0.918; $p=0.261$, respectively) and $\mathrm{Bb}$ after $\mathrm{RT}(p=0.077)$ and did not exceed $0.4^{\circ} \mathrm{C}$ (Table 4). This could be explained by the fact that the male subjects were well-trained (when compared with female subjects) and would have been able to produce a reduced amount of metabolic heat through the oxidation process. On the other hand, this can be explained by the fact that during RT these muscles work at a relatively lower intensity when compared with other muscles. This is in agreement with Fortney and Vroman (1985) who suggested that the internal temperature of the body can be influenced by exercise intensity. In the authors' opinion, further research is needed to establish the asymmetries of $T_{s k}$.

According to the authors' knowledge, the present study is the first thermographic examination of subjects practising RT. The authors support the view that measuring energetic-metabolic activity of muscles or muscles group can be used as a comparative tool for establishing the efficiency of different healthy training methods and provide information on electric muscular activity and the response of $T_{s k}$ under the influence of healthy exercise. Changes in $T_{s k}$ provide information on the efficiency of the endogenous heat removal system during healthy training and can provide information on metabolic changes associated with a return to homeostasis after healthy training.

\section{Conclusions}

The thermographic data obtained in this study indicates that left-right $\Delta T_{s k}$ was statistically significant for $\mathrm{Of}, \mathrm{Bf}, \mathrm{Bb}$ and $\mathrm{Tb}$ in female subjects. In male subjects, right-left $\Delta T_{s k}$ was statistically significant, except for $\mathrm{Tb}$ 
before and after RT as well as Bb after RT. Further research is needed to find normal or maximum $T_{s k}$ asymmetries in healthy subjects.

In the present study, thermographic data indicated that median $T_{s k}$ before and after RT was lower in almost all of the examined ROIs in females compared to males, except of the left and right Qf after RT. These findings indicate that the thermoregulatory responses in skin blood flow may be gender-dependent.

In the authors' opinion, thermography is a non-invasive, safe and lowcost method that can used to measure the irradiated energy released from the body, thus recording the physiological response of the skin to RT.

The authors agree with the data obtained by Hunold et al. (1992), which show that PA caused $T_{s k}$ changes not only within the area of the working muscles but it also affected $T_{s k}$ of other areas.

\section{Acknowledgements}

The authors wish to thank all the participants of the study for their willingness and perseverance. Special thanks goes to Adam Adamowicz, Eng. PhD (Bialystok University of Technology) for his kind assistance during thermal image acquisition and processing.

\section{R E F E R E N C E S}

Cavill, N., Kahlmeier, S., \& Racioppi, F. (Eds.). (2006). Physical activity and health in Europe - evidence for action. Denmark: WHO.

Chudecka, M., \& Lubkowska, A. (2010). Temperature changes of selected body's surfaces of hand-ball players in the course of training estimated by thermovision, and the study of the impact of physiological and morphological factors on the skin temperature. Journal of Thermal Biology, 35(8), 379-385.

Chudecka, M., \& Lubkowska, A. (2012). The use thermal imaging to evaluate body temperature changes of athletes during training and a study on the impact of physiological and morphological factors on skin temperature. Human movement, 13(1), 33-39.

Chudecka, M., \& Lubkowska, A. (2015). Termal maps of young women and men. Infrared Physics and Technology, 69, 81-87.

Coh, M., \& Sirok, B. (2007). Use of the thermovision method in sport training. Facta Universitatas: Series Physical Education and Sport, 5(1), 85-94.

Corbin, Ch. B., Welk, G. J., Corbin, W. R., \& Welk, K. A. (2009). Concepts of Physical Fitness: Active Lifestyles for Wellness. Boston: McGraw Hill.

Coulter, H. D. (2010). Anatomy of Hatha Yoga: A Manual for Students, Teachers, and Practitioner's. USA: Publisher Body and Breath. 
Dwayer, G. B., \& Davis, S. E. (2005). ACSM's Health-Related Physical Fitness Assessment Manual. American College of sports medicine: Wolters Kluwer, Lippincott Williams \& Wilkins.

EWEC (2015). The Global Strategy for Women's, Children's and Adolescents' Health. Retrieved from http://www.everywomaneverychild.org/

Fernández-Cuevas, I., Bouzas Marins, J. C., Arnaiz Lastras, J., Gómez Carmona, P. M., Pińonosa Cano, S., Garcia-Conceptión, M. A., \& SilleroQuintana, M. (2015). Classification of factors influencing the use of infrared thermography in humans: A review. Infrared Physics and Technology, 71, $28-55$.

Fortney, S. M., \& Vroman, N. B. (1985). Exercise, performance and temperature control: temperature regulation during exercise and implications for sports performance and training. Sports Medicine, 2(1), 8-20.

Griffin, S. (2006). Training the over 50's. Developing specific programmers for older clients. London: A\&C Black.

Hashiguchi, N., Feng, Y., \& Tochihara, Y. (2010). Gender differences in thermal comfort and mental performance at different vertical air temperatures. $E u$ ropean Journal of Applied Physiology, 109(1), 41-48.

Hass, Ch. J., Feigenbaum, M. S., \& Franklin, B. A. (2001). Prescription of resistance training for healthy populations. Sports Medicine, 31(14), 953-964.

Heszen, I. (2005). Zmienność wymiarów zdrowia na przestrzeni życia człowieka. In D. Kubacka-Jasiecka \& T. M. Ostrowski (Eds.), Psychologiczny wymiar zdrowia, kryzysu i choroby (pp. 21-22). Kraków: Wydawnictwo Uniwersytetu Jagiellońskiego.

Hildebrandt, C., Raschner, C., \& Ammer, K. (2010). An overview of Recent Application of Medical Infrared Thermography in Sports Medicine in Austria. Sensors, 10(5), 4700-4715.

Hunold, S., Mietzsc, E., \& Werner, J. (1992). Termographic studies on patterns of skin temperature after exercise. European Journal of Applied Physiology, $65(6), 550-554$.

Isii, Y., Matsukawa, K., Tsuchimochi, H., \& Nakamoto, T. (2007). Ice-water hand immersion causes a reflex decrease in skin temperature in the contralateral hand. Journal of Physiological Sciences, 57(4), 241-248.

Jones, B. F., \& Plassmann, P. (2002). Digital infrared thermal imaging of human skin. IEEE Engineering in Medicine and Biology Magazine, 21(6), 41-48.

Kenney, W. L., \& Munce, T. A. (2003). Invited review: aging and human temperature regulation. Journal of Applied Physiology, 95(6), 2598-2603.

Klavestrand, J., \& Vingård, E. (2009). The relationship between physical activity and health-related quality of life: a systematic review of current evidence. Scandinavian Journal of Medicine \& Science in Sports, 19(3), 300-312.

Liu, Y., Mimura, K., Wang, L., \& Ikuda, K. (2003). Physiological benefits of 24-style taijiquan exercise in middle-aged women. Journal of Physiological Anthropology and Applied Human Science, 22, 219-225. 
Merla, A., Mattei, P. A., Di Donato, L., \& Romani, G. (2010). Thermal imaging of cutaneous temperature modifications in runners during graded exercise. Annals of Biomedical Engineering, 38(1), 158-163.

Novotny, J., Rybarova, S., Zacha, D., Bernacikova, M., \& Ramadan, W. A. (2015). The influence of breaststroke swimming on the muscle activity of young men in thermographic imaging. Acta Bioengineering and Biomechanics, 17(2), $121-129$.

Starosta, W. (1997). Znaczenie aktywności ruchowej w zachowaniu i polepszaniu zdrowia człowieka. Lider, 75, 3-9.

Thompson, W. R. (2011). Worldwide Survey of Fitness Trends for 2012. ACSM'S Health \& Fitness Journal, 15(6), 9-18.

Uematsu, S. (1985). Thermographic imaging of cutaneous sensory segment in patients with peripheral nerve injury skin-temperature stability between sides of the body. Journal of Neurosurgery, 62(5), 716-720.

Vardasca, R., Ring, E. F. J., Plassmann, P., \& Jones, C. D. (2012). Thermal symmetry of the upper and lower extremities in healthy subjects. Thermology International, 22(2), 53-60.

Warburton, D. E. R., Nicol, C. W., \& Bredin, S. S. D. (2006). Health benefits of physical activity: the evidence. Canadian Medical Association Journal, $174(6), 801-809$.

Whaley, M. H., Kaminsky, L. A., Dwyer, G. B., Getchell, L. H., \& Norton, J. A. (1992). Predictors of over-and under achievement of age-predicted maximal heart rate. Medicine \& Science in Sports \& Exercise, 24(10), 1173-1179.

Zaproudina, N. (2012). Methodological Aspect of Use of Infrared Thermography in Healthy Individuals and Patients with Non-specific Musculoskeletal Disorders (Dissertation in Health Science no 92). Institute of Biomedicine, School of Medicine, Faculty of Health Sciences, University of Eastern Finland.

Zuzda, J., \& Latosiewicz, R. (2010). Innovative Program of Recreational Classes Using Rotational Movements. Białystok: Oficyna Wydawnicza Politechniki Białostockiej.

Zuzda, G. J., Latosiewicz, R., O'Hara, K., Esteves, D., \& Bras, R. (2013a). Effects of Rotational Exercise on Fitness Training. Medicine \& Science in Sport \& Exercise. Supplement to the Official Journal of the ACSM, 45(5S): 2798, 661.

Zuzda, G. J., Latosiewicz, R., \& Barańczuk, E. (2013b). Influence of Rotational Training on VO2max, Strength and Flexibility. In D. Kozłowska \& K. L. Sobolewski (Eds.), Movement and Health. Selected Problems (pp. 193-201). Białystok: Wyższa Szkoła Wychowania Fizycznego i Turystyki w Białymstoku. 